\title{
Tumour-necrosis factor-A polymorphisms and gastric cancer risk:
}

\section{a meta-analysis}

\author{
F Gorouhi', F Islami ${ }^{2,3}$, H Bahrami ${ }^{4}$ and F Kamangar ${ }^{*, 5}$ \\ 'Department of Medicine, The Reading Hospital and Medical Center, West Reading, PA, USA; ${ }^{2}$ Digestive Disease Research Center, Medical Sciences/ \\ University of Tehran, Tehran, Iran; ${ }^{3}$ International Agency for Research on Cancer, Lyon, France; ${ }^{4}$ Departments of Medicine and Epidemiology, Johns \\ Hopkins Schools of Medicine and Public Health, The Johns Hopkin's University, Baltimore, MD, USA; ${ }^{5}$ Division of Cancer Epidemiology and Genetics, \\ National Cancer Institute, National Institutes of Health, Bethesda, MD, USA
}

Inflammation is one of the early phases in the development of gastric cancer. Therefore, several studies have examined the association of polymorphisms in tumour-necrosis factor-A gene (TNF-A) with gastric cancer risk. This meta-analysis reviews and summarises published evidence for these associations. Searching several databases yielded 24 independent studies that reported on the associations between TNF-A polymorphisms and gastric cancer risk. We analysed available data for the most commonly investigated polymorphisms: TNF-A -308G > A (23 studies), TNF-A -238G > A (9 studies), and TNF-A -857C > T (5 studies). Summary odds ratios (ORs) and $95 \%$ confidence intervals $(95 \% \mathrm{Cls}$ ) were calculated in the random-effects model using the DerSimonian-Laird method. Q-statistic and $I^{2}$-statistic were calculated to examine heterogeneity, and funnel plots were plotted to examine small study effects. The overall ORs (95\% Cls) for AG and AA genotypes vs GG genotype for TNF-A - 308 were I.09 (0.94$1.27)$ and I.49 (I.II-1.99), respectively. For TNF-A - 238, the corresponding ORs (95\% Cls) were I.05 (0.84- I.33) and I.25 (0.305.26), respectively. The overall ORs ( $95 \% \mathrm{Cls}$ ) for CT and TT genotypes (vs CC) for TNF-A - 857 were 1.06 (0.89-1.27) and I.57 $(0.91-2.70)$, respectively. The statistically significant association between TNF-A - 308GG and gastric cancer was limited to western populations. This association showed little heterogeneity $\left(I^{2}=0\right)$ and remained consistently strong when analyses were limited to anatomic and histologic subtypes of gastric cancer, or limited to studies in which genotype frequencies were in Hardy-Weinberg equilibrium, or limited to larger studies. These same subgroup analyses did not change results associated with other polymorphisms. In conclusion, TNF-A -308AA genotype was associated with a statistically significant increased risk of gastric cancer, whereas other studied polymorphisms were not. The association between TNF-A -857TT genotype and gastric cancer was near significant, and may become significant if more studies are published.

British Journal of Cancer (2008) 98, |443- |45।. doi:I0.1038/sj.bjc.6604277 www.bjcancer.com

Published online 4 March 2008

(c) 2008 Cancer Research UK

Keywords: TNF; gastric cancer; polymorphism; inflammation; genetic

Inflammation in the form of chronic superficial gastritis is one of the early phases in the development of gastric cancer (Correa, 1992). Therefore, a stronger inflammatory response by the host may modify gastric cancer risk. The first published epidemiologic evidence for this hypothesis came from a study published in Nature, which showed an increased risk of gastric cancer and its precursor lesions associated with proinflammatory polymorphisms in interleukin-1B $(I L-1 B)$ and $I L-1 R N$ genes (El Omar et $a l, 2000)$. Subsequent studies presented more data on the associations between several proinflammatory polymorphisms and gastric cancer. Some studies suggested that these polymorphisms increase gastric cancer risk, and, in some studies, this increase in risk was observed only in certain subgroups such as certain

\footnotetext{
* Correspondence: Dr F Kamangar, Division of Cancer Epidemiology and Genetics, National Cancer Institute, National Institutes of Health, 6120 Executive Blvd, Room 3034, Bethesda, MD 20892-7232, USA; E-mail: kamangaf@mail.nih.gov

Received 28 November 2007; accepted 24 January 2008; published online 4 March 2008
}

anatomical subsites (ie, noncardia) (El Omar et al, 2003) or histological subtypes (ie, intestinal type) (Machado et al, 2001) of gastric cancer. Other studies, however, showed no association or even inverse associations.

In addition to polymorphisms in interleukin genes, the polymorphisms in the promoter region of tumour-necrosis factor-A (TNF-A) gene have been extensively studied in relation to gastric cancer. Three polymorphisms in TNF- $A$ genes have been studied more than the other polymorphisms. TNF-A $-308 \mathrm{G}>\mathrm{A}$ is associated with an increased production of TNF- $\alpha$ (Jang et al, 2001), which is a central mediator of the immune response and shares many biologic properties with IL-1. The function and significance of TNF-A $-238 \mathrm{G}>\mathrm{A}$ is less clear, but because a putative repressor site is located in a 25-base stretch that includes position -238 , this polymorphism may be functional (Jang et al, 2001). TNF-A $-857 \mathrm{C}>\mathrm{T}$ is also associated with higher transcriptional activity of TNF-A (Hohjoh and Tokunaga, 2001).

Since the previous results have been inconclusive regarding the associations between TNF- $A$ genotypes and gastric cancer risk, 
the purpose of this meta-analysis is to review studies that have examined those polymorphisms. Where possible, we examine these associations by anatomical or histological subtypes of gastric cancer, and by Helicobacter pylori positivity.

\section{METHODS}

\section{Selection of studies}

We conducted a comprehensive search by examining several databases for all papers that had been published on the association between TNF-A polymorphisms and gastric cancer risk. All results were updated on 15 October 2007. The following terms were used in PubMed Databases search: ('Interleukins' [MeSH] OR 'Tumor Necrosis Factor-alpha' [MeSH] OR (Tumor Necrosis) OR TNF) AND ('Stomach Neoplasms' [MeSH] OR (gastric cancer) OR (stomach cancer)) AND ('Polymorphism, Genetic' [MeSH] OR polymorphism OR polymorphisms). The following terms were used in ISI Database search: $(\mathrm{TS}=$ (Interleukins) OR TS $=$ (Tumor Necrosis Factor-alpha) OR $\mathrm{TS}=$ (Tumor Necrosis) OR $\mathrm{TS}=(\mathrm{TNF}))$ AND $(\mathrm{TS}=($ Stomach Neoplasms $)$ OR TS $=($ gastric cancer) $\mathrm{OR} T S=($ stomach cancer $))$ AND $(\mathrm{TS}=($ Polymorphism, Genetic) $\mathrm{OR} T S=($ polymorphism) $\mathrm{OR} T S=($ polymorphisms $)$ ). Other databases and search terms were MedCarib, LILACS, IMEMR, IndMed, and PAHO databases, searched for (gastric OR stomach) AND (cancer OR carcinoma OR neoplasms); IMSEAR database, searched for combinations of gastric or stomach with cancer or carcinoma or neoplasms; and J-EAST database, searched for combinations of gastric or stomach with cancer or carcinoma or neoplasms plus polymorphism. In addition, references of cited articles were reviewed.

Two of the authors reviewed results of each of the database searches to make sure that published papers are not missed. In addition, where overall data were missing, we contacted the authors for further information.

Using these approaches, reports on TNF-A polymorphisms in relation to gastric cancer was found in a total of 29 articles (Jang et al, 2001; Wu et al, 2002, 2003, 2004; El Omar et al, 2003; GarzaGonzalez et al, 2003, 2005; Machado et al, 2003; Fei et al, 2004; Glas et al, 2004; Lee et al, 2004, 2005; Ohyama et al, 2004; Torres et al, 2004; Guo et al, 2005; Li et al, 2005; Lu et al, 2005; Perri et al, 2005; Rocha et al, 2005; Zambon et al, 2005; Kamangar et al, 2006a; Kim et al, 2006; Morgan et al, 2006; Shirai et al, 2006; Deans et al, 2007; Garcia-Gonzalez et al, 2007; Hou et al, 2007; Seno et al, 2007; Sugimoto et al, 2007). Three studies (Garza-Gonzalez et al, 2003; Wu et al, 2003; Shirai et al, 2006) were excluded from the analyses because their results were reported in other studies (Ohyama et al, 2004; Wu et al, 2004; Garza-Gonzalez et al, 2005). One more study was excluded because the results had been reported for a combination of oesophageal and gastric cancers (Deans et al, 2007). Another study (Seno et al, 2007) was excluded because genotype frequencies were not reported. Therefore, a total of 24 studies were used for calculating summary statistics.

\section{Data extraction and statistical analysis}

For TNF-A -308 (rs1800629) and TNF-A -238 (rs361525), numbers and percentages of GG, GA, and AA genotypes, and for TNF-A -857 (rs1799724), numbers and percentages of CC, CT, and TT genotypes were extracted by case status. For GG and GA vs GG genotypes (TNF-A -308 and -238) and for TT and TC vs CC genotypes (TNF- $A-857$ ), odds ratios (ORs) and $95 \%$ confidence intervals $(95 \%$ CIs $)$ were calculated. We performed similar calculations for AA $v s$ a combination of GA and GG genotypes (TNF-A -308 and -238), and for TT $v s$ a combination of TC and CC genotypes (TNF-A -857) to examine the applicability of recessive models. Likewise, we did similar analyses for a combination of AA and GA vs GG genotypes (TNF-A -308 and -238 ) and for combination of TT and TC $v s$ CC genotypes (TNF-A $-857)$ to examine whether dominant models apply. We used both random-effects models (DerSimonian-Laird method) and fixedeffects models (Mantel-Haenszel method) to calculate overall summary ORs and 95\% CIs. Because these two methods yielded similar results, we chose only random-effects models (Moayyedi, 2004) to present forest plots, and all other analyses described from here onwards.

Some of the published studies found associations only with certain anatomical subsites (ie, noncardia) or histological subtypes (ie, intestinal type) of gastric cancer. Therefore, we calculated summary ORs and 95\% CIs for noncardia cancer, where genotype data were presented by anatomical location, and for intestinal-type cancer, where data on histology were available. We examined the association between TNF- $A-308$ and gastric cancer in studies that reported this association among $H$. pylori-positive subjects. It has been suggested that proinflammatory polymorphisms in interleukins may be associated with higher risk of gastric cancer in western countries, but not in East Asian countries. Therefore, study populations were classified as western (Europe and Americas) vs East Asian (China, Korea, Taiwan, and Japan), and subgroup analyses were performed for each group. In all, 12 studies were from western and 12 studies were from East Asian countries.

We examined the effect of Hardy - Weinberg equilibrium (HWE) on the results of our meta-analysis by calculating summary ORs and 95\% CIs for studies in which these alleles were in HWE among controls. The strategy was to exclude studies in which genotypes violated HWE at $\alpha=0.05$.

We plotted Begg's funnel plot to examine small study effects (Sterne et al, 2001). We also used the method of Begg and Mazumdar (1994) to calculate $P$ for rank correlation and Egger's weighted regression method (Egger et al, 1997) to calculate $P$ for bias. For sensitivity analysis, we excluded smaller studies and recalculated the summary ORs (95\% CIs) using only larger studies.

To examine result heterogeneity among studies, the $Q$-statistic for homogeneity (using Mantel-Haenszel weights) and the $I^{2}$-statistic (Higgins et al, 2003) were calculated. All analyses were done using STATA software, version 9.2 (STATA Corporation, College Station, TX, USA). Throughout the paper, two-sided $P$-values $<0.05$ were considered as statistically significant.

\section{RESULTS}

Twenty-four studies with a total number of 4399 cases and 6855 controls were included in this analysis (Table 1). The most commonly investigated genotypes were TNF-A -308, -238 , and -857 , which were reported in 23,9 , and 5 studies, respectively. Since other genotypes, such as TNF-A -1031, were investigated in a very small number of studies, only data on the above mentioned three genotypes were analysed. Most studies used healthy volunteers or blood donors as control subjects. The frequency of TNF- $A-308 \mathrm{~A}$ and TNF- $A-238 \mathrm{~A}$ alleles ranged from 0.9 to $16.2 \%$ and from 1.2 to $10.3 \%$, respectively. The frequency of TNF-A $-857 \mathrm{~T}$ allele ranged from 14.3 to $19.6 \%$. Median frequencies of TNF-A $-308 \mathrm{~A}$ allele were 12.5 and $6.8 \%$ in western populations and East Asian populations, respectively. Corresponding frequencies for TNF-A $-238 \mathrm{~A}$ allele were 4.9 and $3.8 \%$, and for TNF-A $-857 \mathrm{~T}$ allele were 19.6 and $15.0 \%$, respectively.

\section{TNF- $A-308$}

Study-specific and summary ORs (95\% CIs) are shown in Figure 1A. For all gastric cancers, the random-effect overall ORs (95\% CIs) associated with heterozygous (GA vs GG) and homozygous (AA vs GG) proinflammatory genotypes were 1.09 
Table I Study characteristics

\begin{tabular}{|c|c|c|c|c|c|c|c|c|c|c|c|}
\hline & $\begin{array}{l}\text { First } \\
\text { author }\end{array}$ & Study location & Year $^{a}$ & $\begin{array}{l}\text { Number of } \\
\text { cases/controls }\end{array}$ & $\begin{array}{l}\text { Source of control } \\
\text { selection }\end{array}$ & $\begin{array}{l}\%-308 \mathrm{~A} \text { allele } \\
\text { frequency }\end{array}$ & $\begin{array}{l}\%-238 \mathrm{~A} \text { allele } \\
\text { frequency }^{c}\end{array}$ & $\begin{array}{l}\%-857 \text { T allele } \\
\text { frequency }^{\mathrm{d}}\end{array}$ & $\begin{array}{l}P, \text { HWE } \\
-308^{\mathrm{e}}\end{array}$ & $\begin{array}{c}P, \text { HWE } \\
-238^{f}\end{array}$ & $\begin{array}{r}P, \mathrm{HW} \\
-857^{\mathrm{g}}\end{array}$ \\
\hline 1 & Jang & Korea (E) & 2001 & $52 / 92$ & Healthy volunteers & 3.8 & 7.1 & - & 0.70 & 0.39 & - \\
\hline 2 & Wu & Taiwan (E) & 2002 & $150 / 220$ & Healthy volunteers & 12.0 & 1.8 & - & $<0.01$ & $<0.01$ & - \\
\hline 3 & El-Omar & USA (W) & 2003 & $314 / 210$ & Population based & 15.2 & - & - & 0.55 & - & - \\
\hline 4 & Machado & Portugal (W) & 2003 & 287/304 & Healthy volunteers & 12.7 & - & - & 0.65 & - & - \\
\hline 5 & Fei & China (E) & 2004 & $56 / 164$ & Healthy volunteers & 6.7 & - & - & 0.12 & - & - \\
\hline 6 & Glas & Germany (W) & 2004 & $88 / 145$ & Healthy volunteers & 15.2 & 3.8 & - & 0.67 & 0.63 & - \\
\hline 7 & Lee SG & Korea (E) & 2004 & $341 / 261$ & Healthy volunteers & 8.4 & 4.8 & 15.9 & 0.49 & 0.42 & 0.85 \\
\hline 8 & Torres & Colombia (W) & 2004 & $44 / 66$ & Clinic based & 7.6 & - & - & 0.51 & - & - \\
\hline 9 & Wu & Taiwan (E) & 2004 & $204 / 210$ & Healthy volunteers & 12.4 & 1.7 & 14.3 & $<0.01$ & $<0.01$ & 0.20 \\
\hline 10 & Ohayama & Japan (E) & 2004 & $300 / 472$ & Clinic based & - & - & 18.6 & - & - & 0.90 \\
\hline 11 & Garza-Gonzalez & Mexico (W) & 2005 & $63 / 215$ & Clinic based & 8.6 & - & - & 0.61 & - & - \\
\hline 12 & Guo & China (E) & 2005 & $264 / 437$ & Healthy volunteers & 5.9 & - & - & $<0.01$ & - & - \\
\hline 13 & Lee JY & Korea (E) & 2005 & $122 / 120$ & Healthy volunteers & 7.1 & - & - & 0.40 & - & - \\
\hline 14 & $\mathrm{Li}$ & China (E) & 2005 & $59 / 264$ & Healthy volunteers & 7.2 & - & - & 0.56 & - & - \\
\hline 15 & Lu & China (E) & 2005 & $250 / 300$ & Population based & 4.7 & 3.8 & - & 0.08 & 0.49 & - \\
\hline 16 & Perri & Italy (W) & 2005 & $184 / 362$ & Healthy volunteers & 10.9 & - & - & 0.15 & - & - \\
\hline 17 & Rocha & Brazil (W) & 2005 & $161 / 535$ & Healthy volunteers & 13.9 & - & - & 0.34 & - & - \\
\hline 18 & Zambon & Italy $(W)$ & 2005 & $129 / 644$ & Clinic based & 12.3 & 5.9 & 19.6 & 0.90 & 0.38 & $<0.01$ \\
\hline 19 & Kamangar & Finland $(\mathrm{W})$ & 2006 & $112 / 208$ & Healthy cohort subjects & 13.5 & 1.2 & - & 0.29 & 0.86 & - \\
\hline 20 & Kim & Korea (E) & 2006 & $237 / 461$ & Healthy volunteers & 6.8 & - & - & 0.91 & - & - \\
\hline 21 & Morgan & Honduras (W) & 2006 & $168 / 161$ & Population based & 3.7 & - & - & 0.62 & - & - \\
\hline 22 & Hou & Poland (W) & 2007 & $305 / 427$ & Population based & 16.2 & - & - & 0.19 & - & - \\
\hline 23 & Sugimoto & Japan (E) & 2007 & $105 / 172$ & Clinic based & 0.9 & - & 15.7 & 0.91 & - & 0.11 \\
\hline 24 & Garcia-Gonzalez & Spain (W) & 2007 & $404 / 404$ & Healthy volunteers & 11.3 & 10.3 & - & 0.35 & 0.01 & - \\
\hline
\end{tabular}

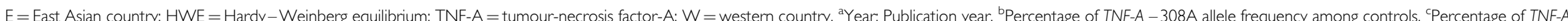
-238 A allele frequency among controls. ${ }^{\mathrm{d}}$ Percentage of TNF-A - 857 T allele frequency among controls. ${ }^{\mathrm{e}} \mathrm{P}$-value for HWE for TNF-A - 308 polymorphism among controls. ${ }^{\mathrm{f}} \mathrm{P}$-value for HWE for TNF-A - 238 polymorphism among controls. ${ }^{\mathrm{P}} \mathrm{P}$-value for HWE for TNF-A -857 polymorphism among controls. 

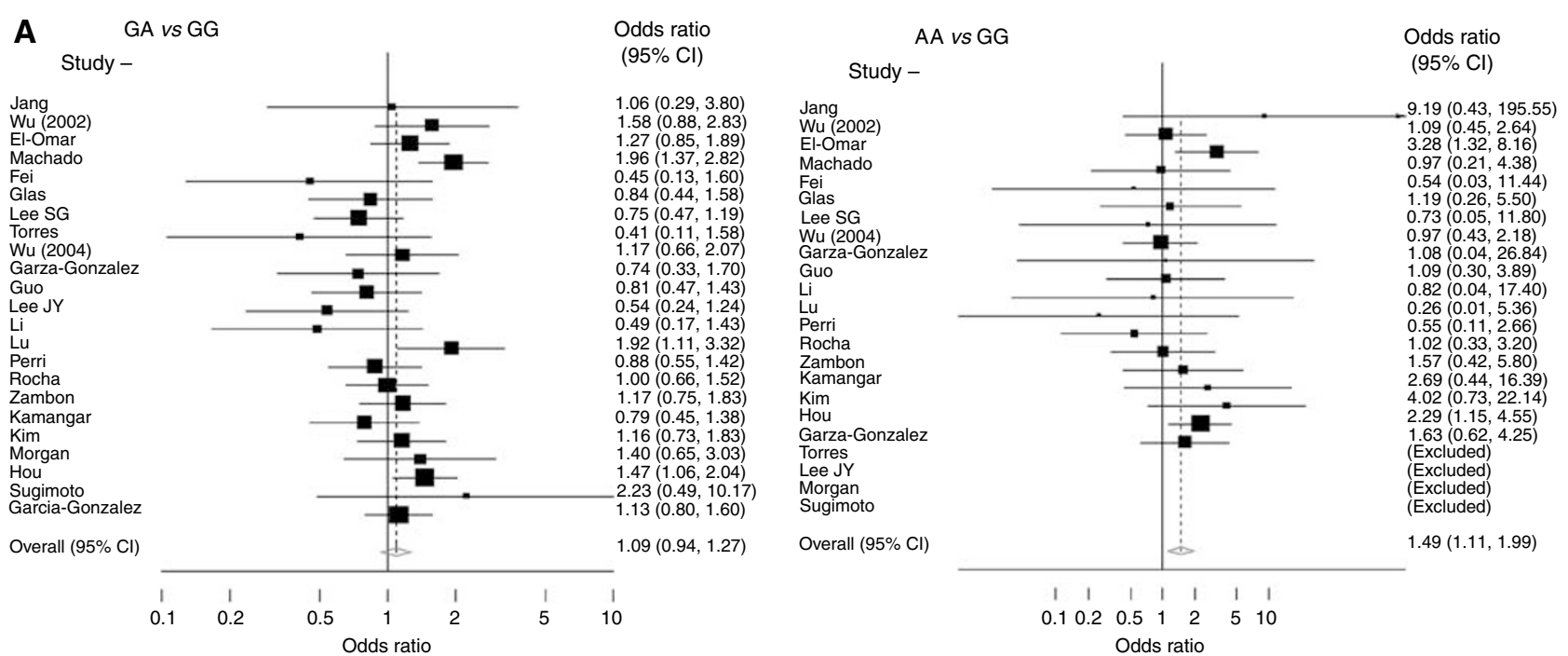

B
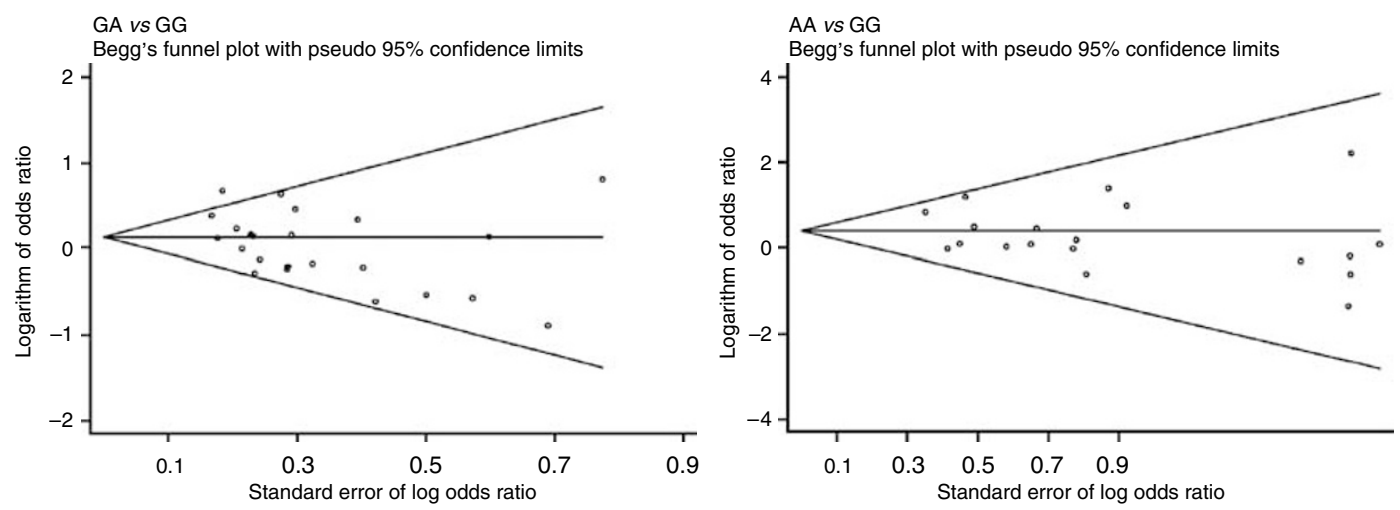

Figure I The association between TNF-A -308 and gastric cancer (GA and AA genotypes vs GG). (A) Forest plot - studies are sorted in order of publication year. (B) Begg's funnel plots for the associations.

(0.94-1.27) and $1.49(1.11-1.99)$, respectively, and the corresponding fixed-effect ORs (95\% CIs) were $1.14(1.02-1.27)$ and 1.51 (1.14-1.99), respectively. Recessive model was the best-fitting inheritance model for TNF-A -308. However, because GG genotype was much more frequent than GA and AA genotypes, comparing GA + GG vs AA genotype did not have a material effect on the test power. Therefore, the results are reported separately for GA $v s$ GG and AA vs GG genotypes.

Table 2 summarises overall and subgroup-specific summary ORs and 95\% CIs. Only a fraction of studies presented data on subgroups. For example, only 6 out of the 23 studies reported their results by intestinal vs diffuse histology types. Among these, summary ORs (95\% CIs) for GA $v s$ GG and AA vs GG genotypes were $1.17(0.85-1.59)$ and $2.88(1.74-4.77)$ for noncardia cancers and $0.98(0.68-1.40)$ and $2.17(1.17-4.03)$ for intestinal-type gastric cancers, respectively. When we limited our analysis to $H$. pylori-positive cases and controls, these ORs (95\% CIs) were 0.66 $(0.33-1.30)$ and $3.23(0.10-99.4)$, respectively. The summary ORs (95\% CIs) for GA vs GG and AA vs GG genotypes were 1.14 (0.95$1.37)$ and $1.74(1.21-2.51)$ for western countries, and $1.02(0.78-$ $1.34)$ and $1.14(0.70-1.84)$ for eastern countries, respectively.

In three studies, the distributions of TNF- $A-308$ genotypes among controls were not in HWE (Table 1). Limiting the analysis to the studies with HWE, the summary ORs (95\% CIs) for GA $v s$ GG and AA $v s$ GG genotypes were $1.08(0.91-1.28)$ and $1.73(1.22-$ 2.44), respectively.

Figure 1B shows Begg's funnel plot for the association between TNF-A -308 and gastric cancer. This figure shows logarithm of OR
( $Y$ axis) $v s$ its standard error (SE) ( $X$ axis). Smaller studies have larger SEs, therefore points showing these studies are in the righthand side of the graph. For GA vs GG genotypes, there was evidence for bias using Egger's weighted regression method ( $P$ for bias $=0.03)$ and using the method of Begg and Mazumdar $(P=0.07)$. There was no evidence of bias for AA $v s$ GG genotypes using either Egger's method ( $P$ for bias $=0.44$ ) or Begg's method $(P=0.87)$. We excluded small studies, defined as those having an $\mathrm{SE}>0.5$. After these exclusion, the summary OR $(95 \% \mathrm{CI})$ changed to $1.13(0.97-1.32)$ for GA $v s$ GG, and $1.68(1.08-2.61)$ for AA $v s$ GG.

Table 2 shows the $Q$ - and $I^{2}$-statistics for the overall and subgroup analyses. For the overall analysis, the $Q$-statistic was significant $(P=0.02)$ and $I^{2}(34 \%)$ showed a moderate variation for GA vs GG genotypes. For AA vs GG genotypes, the $Q$-statistic was not significant $(P=0.74)$ and $I^{2}$ was equal to zero. Subgroup analyses showed similar patterns as overall analyses. While for most subgroup analyses, the $P$-value for GA $v s$ GG genotypes was significant or remained close to significance level and $I^{2}$ showed moderate heterogeneity among studies, $P$ for heterogeneity was not significant for AA vs GG genotypes (Table 2).

\section{TNF-A -238}

Figure 2A summarises the ORs and 95\% CIs for the associations between TNF- $A-238 \mathrm{~A}$ carrying genotypes and gastric cancer risk. For all gastric cancers, the random-effect overall ORs (95\% CIs) were $1.05(0.84-1.33)$ for GA $v s$ GG genotypes and $1.25(0.30-5.26)$ 
Table 2 Overall and group-specific summary statistics for TNF-A -308 , TNF-A -238 , and TNF-A -857 and gastric cancer

\begin{tabular}{|c|c|c|c|c|c|c|c|}
\hline & Number of studies & Polymorphisms & Q-statistic ${ }^{a}$ & $P$-value ${ }^{b}$ & $I^{2}(\%)^{c}$ & Random-effect OR $(95 \% \mathrm{Cl})$ & Fixed-effect OR $(95 \% \mathrm{Cl})$ \\
\hline \multicolumn{8}{|l|}{ TNF-A - $308(4099 / 6383)^{d}$} \\
\hline \multirow{2}{*}{ All gastric cancers } & 23 & GA vs GG & 36.43 & 0.03 & 40 & $1.09(0.94-1.27)$ & $1.14(1.02-1.27)$ \\
\hline & $19^{\mathrm{e}}$ & AA vs GG & 13.77 & 0.74 & 0 & $1.49(1.11-1.99)$ & $1.51(1.14-1.99)$ \\
\hline \multirow[t]{2}{*}{ Noncardia cancers } & 6 & GA vs GG & 11.80 & 0.04 & 58 & $1.17(0.85-1.59)$ & $1.23(1.02-1.49)$ \\
\hline & 6 & $A A$ vs GG & 4.18 & 0.52 & 0 & $2.88(1.74-4.77)$ & $2.97(1.83-4.84)$ \\
\hline \multirow[t]{2}{*}{ Intestinal-type cancers } & 6 & GA vs GG & 11.68 & 0.04 & 57 & $0.98(0.68-1.40)$ & $1.03(0.83-1.29)$ \\
\hline & 6 & AA vs GG & 4.08 & 0.44 & 0 & $2.17(1.17-4.03)$ & $2.00(1.11-3.61)$ \\
\hline \multirow[t]{2}{*}{ Helicobacter pylori-positive subjects } & 3 & GA vs GG & 4.03 & 0.13 & 50 & $0.66(0.33-1.30)$ & $0.77(0.51-1.15)$ \\
\hline & $2^{\mathrm{e}}$ & AA vs GG & 2.63 & 0.11 & 62 & $3.23(0.10-99.84)$ & $4.05(0.9|-| 8.04)$ \\
\hline \multirow[t]{2}{*}{ Western populations } & 12 & GA vs GG & 18.37 & 0.07 & 40 & $1.14(0.95-1.37)$ & $1.19(1.04-1.36)$ \\
\hline & $10^{\mathrm{e}}$ & $A A$ vs GG & 6.53 & 0.69 & 0 & $1.74(1.21-2.51)$ & $1.76(1.24-2.50)$ \\
\hline \multirow[t]{2}{*}{ East Asian population } & 11 & GA vs GG & 16.80 & 0.08 & 40 & $1.02(0.78-1.34)$ & $1.03(0.85-1.25)$ \\
\hline & $9^{e}$ & AA vs GG & 5.36 & 0.72 & 0 & $1.14(0.70-1.84)$ & $1.15(0.72-1.83)$ \\
\hline \multirow[t]{2}{*}{ Studies in HWE } & 20 & GA vs GG & 33.83 & 0.02 & 44 & $1.08(0.91-1.28)$ & $1.14(1.01-1.28)$ \\
\hline & $16^{e}$ & AA vs GG & 11.28 & 0.73 & 0 & $1.73(1.22-2.44)$ & $1.73(1.25-2.41)$ \\
\hline \multicolumn{8}{|l|}{ TNF-A - $238(1730 / 2484)^{d}$} \\
\hline \multirow[t]{2}{*}{ All gastric cancers } & 9 & GA vs GG & 6.87 & 0.55 & 0 & $1.05(0.84-1.33)$ & $1.04(0.83-1.31)$ \\
\hline & $6^{\mathrm{e}}$ & AA vs GG & 11.12 & 0.05 & 55 & $1.25(0.30-5.26)$ & $0.87(0.41-1.87)$ \\
\hline \multirow[t]{2}{*}{ Noncardia cancers } & 3 & GA vs GG & 2.39 & 0.30 & 16 & $1.04(0.7 \mid-1.52)$ & $1.01(0.74-1.40)$ \\
\hline & $2^{\mathrm{e}}$ & $A A$ vs GG & 9.49 & $<0.01$ & 89 & $1.38(0.01-157.0)$ & $0.72(0.24-2.09)$ \\
\hline \multirow{2}{*}{ Intestinal-type cancers } & 3 & GA vs GG & 1.80 & 0.41 & 0 & $1.40(0.93-2.10)$ & $1.39(0.93-2.08)$ \\
\hline & $2^{\mathrm{e}}$ & $A A$ vs $G G$ & 0.00 & - & 0 & $0.13(0.01-2.20)$ & $0.13(0.01-2.20)$ \\
\hline H. pylori-positive subjects & 0 & - & - & - & - & - & - \\
\hline \multirow[t]{2}{*}{ Western populations } & 4 & GA vs GG & 2.33 & 0.51 & 0 & $1.05(0.78-1.41)$ & $1.05(0.78-1.41)$ \\
\hline & $2^{\mathrm{e}}$ & AA vs GG & 10.25 & $<0.01$ & 90 & $1.25(0.01-171.9)$ & $0.64(0.22-1.85)$ \\
\hline \multirow[t]{2}{*}{ East Asian populations } & 5 & GA vs GG & 4.54 & 0.34 & 12 & $1.04(0.69-1.58)$ & $1.03(0.72-1.47)$ \\
\hline & $4^{e}$ & $A A$ vs GG & 0.79 & 0.85 & 0 & $1.28(0.39-4.21)$ & $1.30(0.41-4.06)$ \\
\hline \multirow[t]{2}{*}{ Studies in HWE } & 6 & GA vs GG & 6.53 & 0.26 & 23 & $1.08(0.75-1.55)$ & $1.06(0.78-1.42)$ \\
\hline & $3^{\mathrm{e}}$ & AA vs GG & 2.85 & 0.24 & 30 & $4.04(0.57-28.8)$ & $3.79(0.93-15.40)$ \\
\hline \multicolumn{8}{|l|}{ TNF-A - $857(1079 / 1759)^{d}$} \\
\hline \multirow[t]{2}{*}{ All gastric cancers } & 5 & CT vs CC & 1.24 & 0.87 & 0 & $1.06(0.89-1.27)$ & $1.06(0.89-1.27)$ \\
\hline & 5 & $\pi$ vs CC & 5.06 & 0.28 & 21 & $1.57(0.91-2.70)$ & $1.54(0.98-2.43)$ \\
\hline \multirow[t]{2}{*}{ Noncardia cancers } & 1 & $C T$ vs $C C$ & 0.00 & - & 0 & $0.94(0.63-1.4 I)$ & $0.94(0.63-1.41)$ \\
\hline & I & $\pi$ vs CC & 0.00 & - & 0 & $0.75(0.17-3.38)$ & $0.74(0.17-3.38)$ \\
\hline Intestinal-type cancers & 0 & - & - & - & - & - & - \\
\hline H. pylori-positive subjects & 0 & - & - & - & - & - & - \\
\hline \multirow[t]{2}{*}{ Western populations } & I & $C T$ vs $C C$ & 0.00 & - & 0 & $0.94(0.63-1.41)$ & $0.94(0.63-1.41)$ \\
\hline & 1 & TT vs CC & 0.00 & - & 0 & $0.75(0.17-3.38)$ & $0.75(0.17-3.38)$ \\
\hline \multirow[t]{2}{*}{ East Asian populations } & 4 & $C T$ vs $C C$ & 0.81 & 0.85 & 0 & $1.09(0.90-1.33)$ & $1.09(0.90-1.33)$ \\
\hline & 4 & TT vs CC & 4.07 & 0.25 & 26 & $1.73(0.95-3.14)$ & $1.68(1.04-2.72)$ \\
\hline \multirow[t]{2}{*}{ Studies in HWE } & 4 & CT vs CC & 0.81 & 0.85 & 0 & $1.09(0.90-1.33)$ & $1.09(0.90-1.33)$ \\
\hline & 4 & $\pi$ vs CC & 4.07 & 0.25 & 26 & $1.73(0.95-3.14)$ & $1.68(1.04-2.72)$ \\
\hline
\end{tabular}

'Higgins' $I^{2}$-statistic for heterogeneity in random-effect model. 'Number of cases/number of controls. 'Some studies were excluded because of the null values for AA genotype frequency among both cases and controls. 

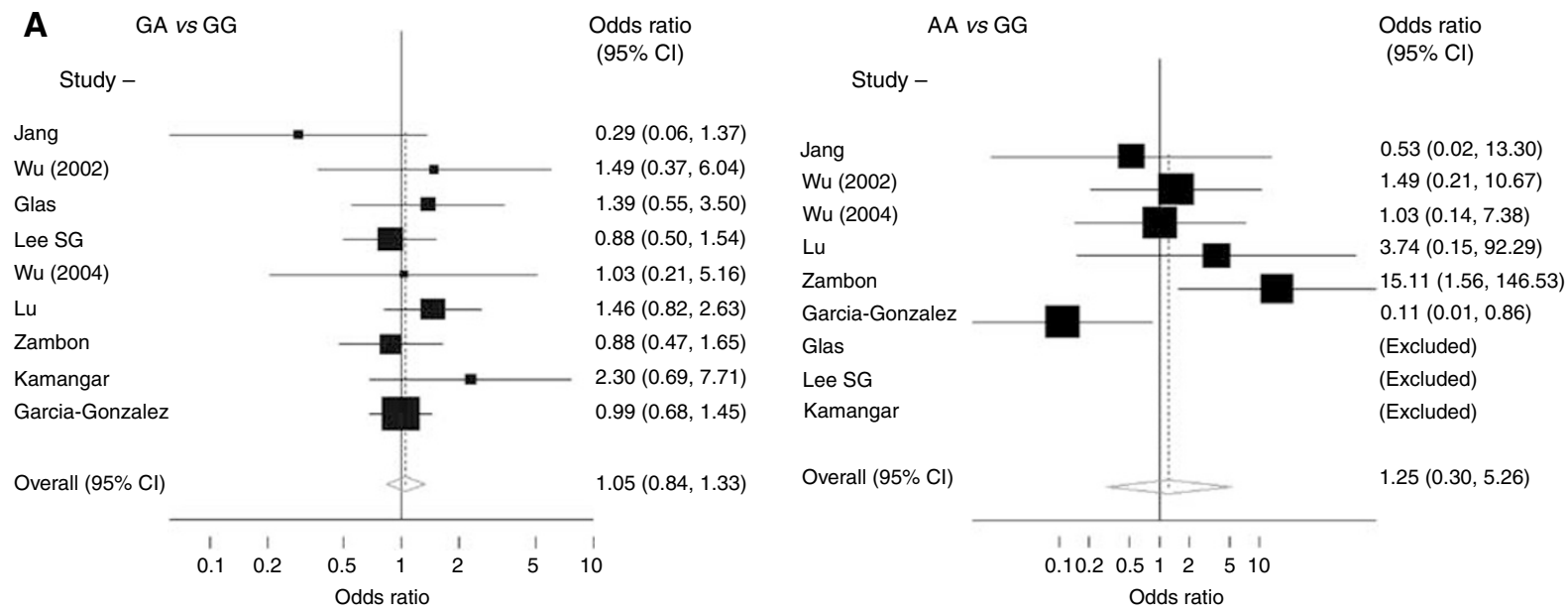

B
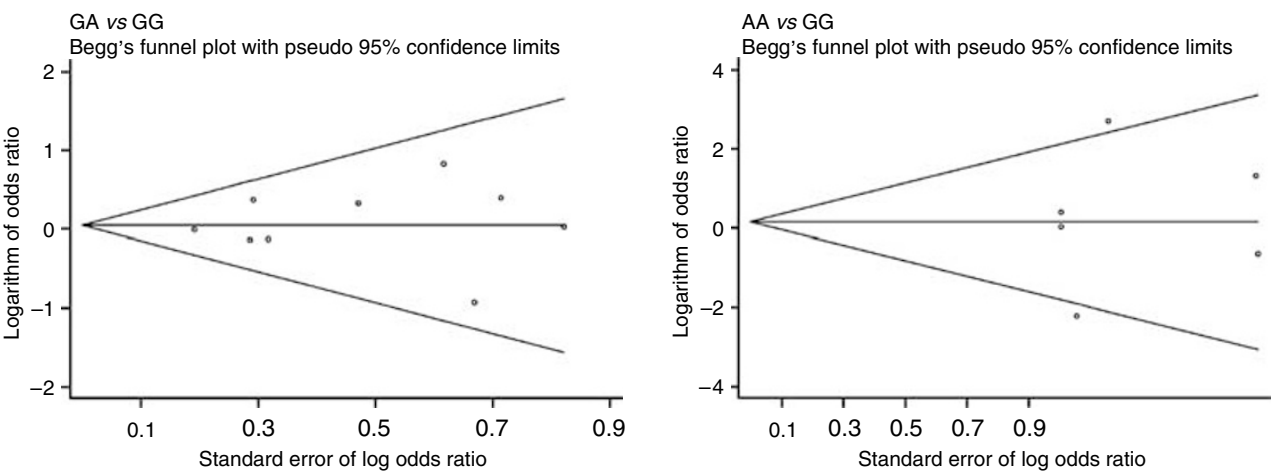

Figure 2 The association between TNF-A -238 and gastric cancer (GA and AA genotypes vs GG). (A) Forest plot - studies are sorted in order of publication year. (B) Begg's funnel plots for the associations.

for AA vs GG genotypes. The fixed-effect ORs (95\% CIs) were 1.04 $(0.83-1.31)$ and $0.87(0.41-1.87)$, respectively. When we investigated the inheritance models, TNF-A -238 showed neither recessive nor dominant models (data not shown). Therefore, the results are reported separately as GA $v s$ GG and AA vs GG genotypes.

For noncardia cancers, the ORs $(95 \% \mathrm{CIs})$ were $1.04(0.71-1.52)$ for GA genotype and $1.38(0.01-157.0)$ for AA genotype. Limiting the results to intestinal-type cancers, the ORs (95\% CIs) were 1.40 $(0.93-2.10)$ for GA genotype and $0.13(0.01-2.20)$ for AA genotype. For this last comparison, one of the three studies was excluded because of the null values for AA genotype frequency among both cases and controls. For studies from western countries, summary ORs (95\% CIs) for GA and AA genotypes were $1.05(0.78-1.41)$ and $1.25(0.01-171.9)$, respectively. For the studies from East Asian countries, these corresponding ORs (95\% CIs) were $1.04(0.69-1.58)$ and $1.28(0.39-4.21)$, respectively.

In three studies, TNF- $A-238$ genotype in control subjects were not in HWE (Table 1). After excluding these three studies, the summary ORs (95\% CIs) for GA and AA genotypes were 1.08 $(0.75-1.55)$ and $4.04(0.57-28.8)$, respectively.

Begg's funnel plot for the association between TNF- $A-238$ and gastric cancer is shown in Figure 2B. For both GA vs GG and AA vs GG genotypes, there was no evidence for bias using either the method of Begg and Mazumdar ( $P$ for rank correlation $=1.00$ and 0.85 , respectively) or Egger's weighted regression method ( $P$ for bias $=0.84$ and 0.75 , respectively). For GA genotype, after excluding studies with an SE $>0.5$, the summary OR $(95 \% \mathrm{CI})$ was $1.04(0.82-1.33)$. For AA genotype, all of the studies had an $\mathrm{SE}>0.5$.
For GA genotype, the $Q$-statistic was nonsignificant for the overall association $(P=0.55)$ and subgroup analyses, and $I^{2}$-statistic showed little heterogeneity among studies (Table 2). For AA genotype, the $Q$-statistic was significant for the overall association $(P=0.05)$ and also for noncardia, intestinal-type, and western populations subgroups, where $I^{2}$-statistic showed moderate-to-high heterogeneity.

\section{TNF-A -857}

Figure $3 \mathrm{~A}$ summarises the ORs and $95 \%$ CIs for the associations between TNF-A $-857 \mathrm{~T}$ carrying genotypes (TC and TT $v s \mathrm{CC}$ ) and gastric cancer risk. For all gastric cancers, the random-effect overall ORs (95\% CIs) for TC vs CC and TT vs CC genotypes were $1.06(0.89-1.27)$ and $1.57(0.91-2.70)$, respectively. The fixedeffect ORs (95\% CIs) were $1.06(0.89-1.27)$ and $1.54(0.98-2.43)$, respectively. Like TNF- $A-238, T N F-A-857$ showed neither recessive nor dominant model. Therefore, the results are reported separately for TC $v s$ CC and TT vs CC genotypes.

Only one study reported the associations between TNF-A -857 and noncardia cancers. This study was also the only study from western countries; the ORs (95\% CIs) for TC and TT genotypes in this study were $0.94(0.63-1.41)$ and $0.75(0.17-3.38)$, respectively. For studies from eastern countries, summary ORs (95\% CIs) for TC and TT genotypes were $1.09(0.90-1.33)$ and $1.73(0.95-3.14)$, respectively.

In one study, TNF- $A-857$ genotypes among controls were not in HWE (Table 1). After excluding that study, the summary ORs (95\% CIs) for TC and TT genotypes were $1.09(0.90-1.33)$ and 1.73 (0.95-3.14), respectively. 

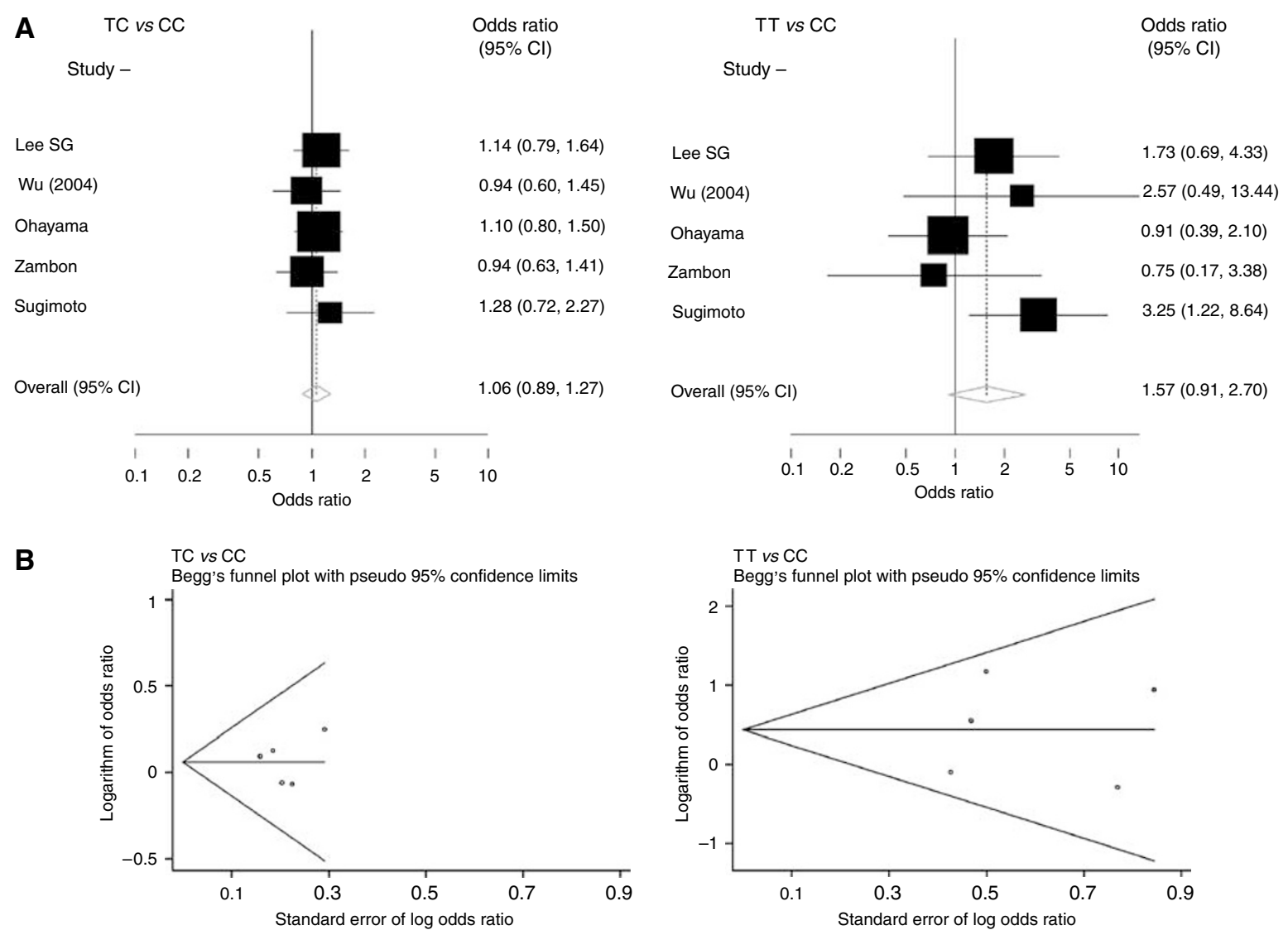

Figure 3 The association between TNF-A -857 and gastric cancer (TC and TT genotypes vs CC). (A) Forest plot - studies are sorted in order of publication year. (B) Begg's funnel plots for the associations.

Begg's funnel plot for the association between TNF- $A-857$ and gastric cancer is shown in Figure 3B. For both TC and CC genotypes, there was no evidence for bias using either the method of Begg and Mazumdar ( $P$ for rank correlation $=0.81$ and 0.46 , respectively) or Egger's weighted regression method ( $P$ for bias $=0.87$ and 0.89 , respectively). For TC $v s$ CC genotypes, none of the studies had an SE $>0.5$. For TT $v s$ CC genotypes, after excluding two studies with SEs $>0.5$, the summary OR (95\% CI) changed to $1.66(0.81-3.42)$.

The $Q$-statistic was nonsignificant for the overall associations and also for the subgroup analyses. Furthermore, $I^{2}$-statistic showed little to moderate heterogeneity among studies (Table 2).

\section{DISCUSSION}

Gastric cancer is the second most common cause of cancer death in the world (Parkin et al, 2005; Kamangar et al, 2006c). Because inflammation is one of the initial phases of gastric carcinogenesis, especially for intestinal-type gastric cancer (Correa, 1992), inflammation-related polymorphisms, including single-nucleotide polymorphisms (SNPs) in TNF-A gene, have been extensively studied in relation to gastric cancer (Camargo et al, 2006). The most extensively studied of these proinflammatory polymorphisms are two linked SNPs in $I L-1 B(-511 \mathrm{C}>\mathrm{T}$ and $-31 \mathrm{~T}>\mathrm{C})$ and a penta-allelic variable number tandem-repeat polymorphism and allele $2\left(I L-1 R N^{\star} 2\right)$. So far, at least three meta-analyses of the associations between these polymorphisms and gastric cancer risk have been published (Camargo et al, 2006; Kamangar et al, 2006b; Wang et al, 2007). However, to our knowledge, no systematic review has been previously published on the association between TNF-A SNPs and gastric cancer. Of the three polymorphisms reviewed in this report, $-308 \mathrm{G}>\mathrm{A}$ is studied more extensively and a biologic role for it has been identified.

An analysis of the 23 studies that presented results on TNF-A $-308 \mathrm{G}>\mathrm{A}$ showed no association between GA genotype ( $v s \mathrm{GG}$ ) and gastric cancer risk. However, there was a statistically significant increased risk associated with AA genotype using both fixed-effects and random-effects models. This association was limited to studies from western countries, and no association was found in studies from East Asian countries. Previous studies have suggested that frequencies of genetic markers often shows high variations among various ethnic and racial groups (Garte et al, 2001; Ioannidis et al, 2004), whereas differences in genetic effects (in terms of ORs) are much less common (Ioannidis et al, 2004). This meta-analysis found that the median prevalence of TNF-A $-308 \mathrm{~A}$ carrier genotypes was almost twice as high in western as in East Asian populations (23.5 vs 13.4\%). However, unlike what has been shown for most previous associations (Ioannidis et al, 2004), the OR associated with AA genotype showed a difference between western and East Asian studies. We cannot explain the reasons for this latter observed difference.

No SNPs have been consistently associated with gastric cancer risk (Gonzalez et al, 2002). Indeed, because several initially promising gene-disease associations gravitated towards null over time (Ioannidis et al, 2001; Kamangar et al, 2006b), it has been suggested that journals should take a cautious approach in publishing such associations (Ioannidis, 2006). However, as shown in the results and discussed below, within the studies from western countries, the association between TNF-A - 308AA genotype and gastric cancer risk seems robust to many tests, including testing for publication bias, heterogeneity, and HWE. Interestingly, a study within the InterLymph Consortium found that this same polymorphism was consistently associated with an increased risk 
of diffuse large B-cell lymphoma with a comparable magnitude of association (Rothman et al, 2006); the ORs associated with GA and AA genotypes ( $v s$ GG genotype) were 1.29 and 1.65, respectively. The studies that participated in this Consortium were all from western countries.

The forest plots for TNF-A - 308AA genotype did not suggest a dominant effect for any single study. We used funnel plots and two formal statistical methods (Egger's weighted regression method and the rank correlation method of Begg and Mazumdar) to detect bias. In general, smaller studies, that is, those with higher SEs, had lower ORs, and there was some evidence for publication bias using both formal methods. However, excluding smaller studies did not materially change the results. In 20 out of 23 studies, distribution of TNF-A -308 among controls was in HWE. Limiting the analyses to these 20 studies, the results remained essentially unchanged. The overall heterogeneity between the studies was very low, as indicated by the $I^{2}$ value of zero.

Since subgroup analyses are often limited by selective reporting of significant subgroup results, such analyses generally need to be interpreted with caution. However, in this report, limiting the results of TNF- $A-308$ polymorphism to noncardia gastric cancers or intestinal-type cancers made little difference. The summary ORs for the AG genotype remained close to null and were nonsignificant, whereas those for the GG genotype remained statistically significantly above one.

We found nine studies that examined the association between $T N F-A-238 \mathrm{G}>\mathrm{A}$ polymorphism and gastric cancer risk. Unlike that for TNF-A - 308G > A polymorphism, a clear biologic role for this polymorphism has not been found (Jang et al, 2001). There was no association between gastric cancer risk and either the GA or the AA genotypes using either random-effects or fixed-effects models. Examining the data by anatomic and histologic subtypes did not make a difference. No statistically significant association was found when data were limited to East Asian populations, western populations, studies with larger sample sizes, or studies in which genotype frequencies were in HWE.

We found only five studies that had examined the association between TNF- $A-857 \mathrm{C}>\mathrm{T}$ polymorphisms and gastric cancer. No evidence was found for the association between CT (vs CC) genotype and gastric cancer. Almost all studies showed null associations, and there was little evidence for heterogeneity. The overall association with the TT genotype, however, was near significant. The overall pattern and magnitude of association is similar to that found for TNF-A $-308 \mathrm{G}>\mathrm{A}$ polymorphism, but

\section{REFERENCES}

Begg CB, Mazumdar M (1994) Operating characteristics of a rank correlation test for publication bias. Biometrics 50: $1088-1101$

Camargo MC, Mera R, Correa P, Peek Jr RM, Fontham ET, Goodman KJ, Piazuelo MB, Sicinschi L, Zabaleta J, Schneider BG (2006) Interleukin-1beta and interleukin-1 receptor antagonist gene polymorphisms and gastric cancer: a meta-analysis. Cancer Epidemiol Biomarkers Prev 15: 1674-1687

Correa P (1992) Human gastric carcinogenesis: a multistep and multifactorial process - First American Cancer Society Award Lecture on Cancer Epidemiology and Prevention. Cancer Res 52: 6735-6740

Deans C, Rose-Zerilli M, Wigmore S, Ross J, Howell M, Jackson A, Grimble $\mathrm{R}$, Fearon K (2007) Host cytokine genotype is related to adverse prognosis and systemic inflammation in gastro-oesophageal cancer. Ann Surg Oncol 14: 329-339

Egger M, Davey SG, Schneider M, Minder C (1997) Bias in meta-analysis detected by a simple, graphical test. BMJ 315: 629-634

Egger M, Schneider M, Davey SG (1998) Spurious precision? Meta-analysis of observational studies. BMJ 316: $140-144$

El Omar EM, Carrington M, Chow WH, McColl KE, Bream JH, Young HA, Herrera J, Lissowska J, Yuan CC, Rothman N, Lanyon G, Martin M, Fraumeni Jr JF, Rabkin CS (2000) Interleukin-1 polymorphisms associated with increased risk of gastric cancer. Nature 404: 398-402 further studies are needed to examine whether gastric cancer is significantly associated with this polymorphism. The studies showed some heterogeneity, with three showing strong positive associations, one showing no association, and one showing an inverse association. We believe that the currently available data do not provide conclusive evidence for the presence of an association, or lack thereof, between TNF-A -857TT genotype and gastric cancer.

Inappropriate selection of controls is a major source of bias in case-control studies. However, control groups for most of the studies used in this meta-analysis were selected from among healthy volunteers or blood donors, and TNF-A polymorphisms are unlikely to be associated with these conditions. Because TNF locus is on chromosome 6 (and not sex chromosomes), the distribution of this polymorphism is not associated with sex. Therefore, in theory, matching for sex should not affect the results.

Strengths of this meta-analysis are including 24 published studies with a large number of cases and controls, presenting data on several relevant methodologic aspects of these studies, subgroup analyses according to predefined criteria, and using other methods to examine the robustness of the summary statistics. We acknowledge that this meta-analysis also has limitations. Combining observational studies conducted in different populations with various qualities of design to obtain summary ORs and 95\% CIs can sometimes be misleading (Shapiro, 1994), and summary statistics need to be interpreted with caution (Egger et al, 1998). However, as mentioned above, there is little evidence for improper selection of control groups or for associations within specific subgroups.

In summary, this systematic review found that TNF- $A-308 \mathrm{AA}$ genotype was moderately associated with an increased risk of gastric cancer. TNF- $A-308 \mathrm{AG}, T N F-A-238 \mathrm{AA}$ or AG, and TNF-A $-857 \mathrm{CT}$ or TT were not statistically significantly associated with gastric cancer risk. It is possible that, with increasing the number of studies, TNF-A $-857 \mathrm{TT}$ may also be associated with an increased risk of gastric cancer.

\section{ACKNOWLEDGEMENTS}

This research was supported in part by the Intramural Research Program of the National Institutes of Health, National Cancer Institute.
El Omar EM, Rabkin CS, Gammon MD, Vaughan TL, Risch HA Schoenberg JB, Stanford JL, Mayne ST, Goedert J, Blot WJ, Fraumeni Jr JF, Chow WH (2003) Increased risk of noncardia gastric cancer associated with proinflammatory cytokine gene polymorphisms. Gastroenterology 124: $1193-1201$

Fei BY, Xia B, Deng CS, Xia XQ, Xie M, Crusius JB, Pena AS (2004) Association of tumor necrosis factor genetic polymorphism with chronic atrophic gastritis and gastric adenocarcinoma in Chinese Han population. World J Gastroenterol 10: 1256-1261

Garcia-Gonzalez MA, Lanas A, Quintero E, Nicolas D, Parra-Blanco A, Strunk M, Benito R, Angel SM, Santolaria S, Sopena F, Piazuelo E, Jimenez P, Pascual C, Mas E, Irun P, Espinel J, Campo R, Manzano M, Geijo F, Pellise M, Gonzalez-Huix F, Nieto M, Espinos J, Tito L, Bujanda L, Zaballa M (2007) Gastric cancer susceptibility is not linked to pro- and anti-inflammatory cytokine gene polymorphisms in whites: a nationwide multicenter study in Spain. Am J Gastroenterol 102: 1878-1892

Garte S, Gaspari L, Alexandrie AK, Ambrosone C, Autrup H, Autrup JL, Baranova H, Bathum L, Benhamou S, Boffetta P, Bouchardy C, Breskvar K, Brockmoller J, Cascorbi I, Clapper ML, Coutelle C, Daly A, Dell'Omo M, Dolzan V, Dresler CM, Fryer A, Haugen A, Hein DW, Hildesheim A, Hirvonen A, Hsieh LL, Ingelman-Sundberg M, Kalina I, Kang D, Kihara 
M, Kiyohara C, Kremers P, Lazarus P, Le Marchand L, Lechner MC, van Lieshout EM, London S, Manni JJ, Maugard CM, Morita S, Nazar-Stewart V, Noda K, Oda Y, Parl FF, Pastorelli R, Persson I, Peters WH, Rannug A, Rebbeck T, Risch A, Roelandt L, Romkes M, Ryberg D, Salagovic J, Schoket B, Seidegard J, Shields PG, Sim E, Sinnet D, Strange RC, Stucker I, Sugimura H, To-Figueras J, Vineis P, Yu MC, Taioli E (2001) Metabolic gene polymorphism frequencies in control populations. Cancer Epidemiol Biomarkers Prev 10: 1239-1248

Garza-Gonzalez E, Bosques-Padilla FJ, El Omar E, Hold G, TijerinaMenchaca R, Maldonado-Garza HJ, Perez-Perez GI (2005) Role of the polymorphic IL-1B, IL-1RN and TNF-A genes in distal gastric cancer in Mexico. Int J Cancer 114: 237-241

Garza-Gonzalez E, Hold G, Perez-Perez GI, Bosques-Padilla FJ, TijerinaMenchaca R, Maldonado-Garza HJ, El Omar E (2003) Role of polymorphism of certain cytokines in gastric cancer in Mexico. Preliminary results. Rev Gastroenterol Mex 68: 107-112

Glas J, Torok HP, Schneider A, Brunnler G, Kopp R, Albert ED, Stolte M, Folwaczny C (2004) Allele 2 of the interleukin-1 receptor antagonist gene is associated with early gastric cancer. J Clin Oncol 22: 4746-4752

Gonzalez CA, Sala N, Capella G (2002) Genetic susceptibility and gastric cancer risk. Int I Cancer 100: 249-260

Guo W, Wang N, Li Y, Zhang JH (2005) Polymorphisms in tumor necrosis factor genes and susceptibility to esophageal squamous cell carcinoma and gastric cardiac adenocarcinoma in a population of high incidence region of North China. Chin Med J (Engl) 118: 1870-1878

Higgins JP, Thompson SG, Deeks JJ, Altman DG (2003) Measuring inconsistency in meta-analyses. BMJ 327: $557-560$

Hohjoh H, Tokunaga K (2001) Allele-specific binding of the ubiquitous transcription factor OCT-1 to the functional single nucleotide polymorphism (SNP) sites in the tumor necrosis factor-alpha gene (TNFA) promoter. Genes Immun 2: 105-109

Hou L, El Omar EM, Chen J, Grillo P, Rabkin CS, Baccarelli A, Yeager M, Chanock SJ, Zatonski W, Sobin LH, Lissowska J, Fraumeni Jr JF, Chow WH (2007) Polymorphisms in Th1-type cell-mediated response genes and risk of gastric cancer. Carcinogenesis 28: 118-123

Ioannidis JP (2006) Journals should publish all 'null' results and should sparingly publish 'positive' results. Cancer Epidemiol Biomarkers Prev 15: 186

Ioannidis JP, Ntzani EE, Trikalinos TA (2004) 'Racial' differences in genetic effects for complex diseases. Nat Genet 36: 1312-1318

Ioannidis JP, Ntzani EE, Trikalinos TA, Contopoulos-Ioannidis DG (2001) Replication validity of genetic association studies. Nat Genet 29: 306-309

Jang WH, Yang YI, Yea SS, Lee YJ, Chun JH, Kim HI, Kim MS, Paik KH (2001) The -238 tumor necrosis factor-alpha promoter polymorphism is associated with decreased susceptibility to cancers. Cancer Lett 166: 41-46

Kamangar F, Abnet CC, Hutchinson AA, Newschaffer CJ, Helzlsouer K, Shugart YY, Pietinen P, Dawsey SM, Albanes D, Virtamo J, Taylor PR (2006a) Polymorphisms in inflammation-related genes and risk of gastric cancer (Finland). Cancer Causes Control 17: 117-125

Kamangar F, Cheng C, Abnet CC, Rabkin CS (2006b) Interleukin-1B polymorphisms and gastric cancer risk - a meta-analysis. Cancer Epidemiol Biomarkers Prev 15: $1920-1928$

Kamangar F, Dores GM, Anderson WF (2006c) Patterns of cancer incidence, mortality, and prevalence across five continents: defining priorities to reduce cancer disparities in different geographic regions of the world. J Clin Oncol 24: 2137-2150

Kim N, Cho SI, Yim JY, Kim JM, Lee DH, Park JH, Kim JS, Jung HC, Song IS (2006) The effects of genetic polymorphisms of IL-1 and TNF-A on Helicobacter pylori-induced gastroduodenal diseases in Korea. Helicobacter 11: $105-112$

Lee JY, Kim HY, Kim KH, Kim SM, Jang MK, Park JY, Lee JH, Kim JH, Yoo JY (2005) Association of polymorphism of IL-10 and TNF-A genes with gastric cancer in Korea. Cancer Lett 225: 207-214

Lee SG, Kim B, Yook JH, Oh ST, Lee I, Song K (2004) TNF/LTA polymorphisms and risk for gastric cancer/duodenal ulcer in the Korean population. Cytokine 28: 75-82

Li C, Xia B, Yang Y, Li J, Xia HH (2005) TNF gene polymorphisms and Helicobacter pylori infection in gastric carcinogenesis in Chinese population. Am J Gastroenterol 100: 290-294

Lu W, Pan K, Zhang L, Lin D, Miao X, You W (2005) Genetic polymorphisms of interleukin (IL)-1B, IL-1RN, IL-8, IL-10 and tumor necrosis factor \{alpha\} and risk of gastric cancer in a Chinese population. Carcinogenesis 26: 631-636

Machado JC, Figueiredo C, Canedo P, Pharoah P, Carvalho R, Nabais S, Castro AC, Campos ML, Van Doorn LJ, Caldas C, Seruca R, Carneiro F, Sobrinho-Simoes M (2003) A proinflammatory genetic profile increases the risk for chronic atrophic gastritis and gastric carcinoma. Gastroenterology 125: $364-371$

Machado JC, Pharoah P, Sousa S, Carvalho R, Oliveira C, Figueiredo C, Amorim A, Seruca R, Caldas C, Carneiro F, Sobrinho-Simoes M (2001) Interleukin $1 \mathrm{~B}$ and interleukin $1 \mathrm{RN}$ polymorphisms are associated with increased risk of gastric carcinoma. Gastroenterology 121: 823-829

Moayyedi P (2004) Meta-analysis: can we mix apples and oranges? Am J Gastroenterol 99: 2297-2301

Morgan DR, Dominguez RL, Keku TO, Heidt PE, Martin CF, Galanko JA, Omofoye OA, Sandler RS (2006) Gastric cancer and the high combination prevalence of host cytokine genotypes and Helicobacter pylori in Honduras. Clin Gastroenterol Hepatol 4: 1103-1111

Ohyama I, Ohmiya N, Niwa Y, Shirai K, Taguchi A, Itoh A, Hirooka Y, Wakai K, Hamajima N, Mori N, Goto H (2004) The association between tumour necrosis factor-alpha gene polymorphism and the susceptibility to rugal hyperplastic gastritis and gastric carcinoma. Eur J Gastroenterol Hepatol 16: $693-700$

Parkin DM, Bray F, Ferlay J, Pisani P (2005) Global cancer statistics, 2002. CA Cancer J Clin 55: 74-108

Perri F, Piepoli A, Bonvicini C, Gentile A, Quitadamo M, Di Candia M, Cotugno R, Cattaneo F, Zagari MR, Ricciardiello L, Gennarelli M, Bazzoli F, Ranzani GN, Andriulli A (2005) Cytokine gene polymorphisms in gastric cancer patients from two Italian areas at high and low cancer prevalence. Cytokine 30: 293-302

Rocha GA, Guerra JB, Rocha AM, Saraiva IE, da Silva DA, de Oliveira CA, Queiroz DM (2005) IL1RN polymorphic gene and cagA-positive status independently increase the risk of noncardia gastric carcinoma. Int $J$ Cancer 115: 678-683

Rothman N, Skibola CF, Wang SS, Morgan G, Lan Q, Smith MT, Spinelli JJ, Willett E, De Sanjose S, Cocco P, Berndt SI, Brennan P, Brooks-Wilson A, Wacholder S, Becker N, Hartge P, Zheng T, Roman E, Holly EA, Boffetta P, Armstrong B, Cozen W, Linet M, Bosch FX, Ennas MG, Holford TR, Gallagher RP, Rollinson S, Bracci PM, Cerhan JR, Whitby D, Moore PS, Leaderer B, Lai A, Spink C, Davis S, Bosch R, Scarpa A, Zhang Y, Severson RK, Yeager M, Chanock S, Nieters A (2006) Genetic variation in TNF and IL10 and risk of non-Hodgkin lymphoma: a report from the InterLymph Consortium. Lancet Oncol 7: 27-38

Seno H, Satoh K, Tsuji S, Shiratsuchi T, Harada Y, Hamajima N, Sugano K, Kawano S, Chiba T (2007) Novel interleukin-4 and interleukin-1 receptor antagonist gene variations associated with non-cardia gastric cancer in Japan: comprehensive analysis of 207 polymorphisms of 11 cytokine genes. J Gastroenterol Hepatol 22: 729-737

Shapiro S (1994) Meta-analysis/Shmeta-analysis. Am J Epidemiol 140: 771 - 778

Shirai K, Ohmiya N, Taguchi A, Mabuchi N, Yatsuya H, Itoh A, Hirooka Y, Niwa Y, Mori N, Goto H (2006) Interleukin-8 gene polymorphism associated with susceptibility to non-cardia gastric carcinoma with microsatellite instability. J Gastroenterol Hepatol 21: 1129-1135

Sterne JA, Egger M, Smith GD (2001) Systematic reviews in health care: investigating and dealing with publication and other biases in metaanalysis. BMJ 323: $101-105$

Sugimoto M, Furuta T, Shirai N, Nakamura A, Xiao F, Kajimura M, Sugimura H, Hishida A (2007) Different effects of polymorphisms of tumor necrosis factor-alpha and interleukin-1 beta on development of peptic ulcer and gastric cancer. J Gastroenterol Hepatol 22: 51-59

Torres MM, Acosta CP, Sicard DM, Groot de Restrepo H (2004) [Genetic susceptibility and risk of gastric cancer in a human population of Cauca, Colombia]. Biomedica 24: 153-162

Wang P, Xia HH, Zhang JY, Dai LP, Xu XQ, Wang KJ (2007) Association of interleukin-1 gene polymorphisms with gastric cancer: a meta-analysis. Int J Cancer 120: $552-562$

Wu MS, Chen LT, Shun CT, Huang SP, Chiu HM, Wang HP, Lin MT, Cheng AL, Lin JT (2004) Promoter polymorphisms of tumor necrosis factoralpha are associated with risk of gastric mucosa-associated lymphoid tissue lymphoma. Int J Cancer 110: 695-700

Wu MS, Huang SP, Chang YT, Shun CT, Chang MC, Lin MT, Wang HP, Lin JT (2002) Tumor necrosis factor-alpha and interleukin-10 promoter polymorphisms in Epstein-Barr virus-associated gastric carcinoma. Infect Dis 185: 106-109

Wu MS, Wu CY, Chen CJ, Lin MT, Shun CT, Lin JT (2003) Interleukin-10 genotypes associate with the risk of gastric carcinoma in Taiwanese Chinese. Int J Cancer 104: 617-623

Zambon CF, Basso D, Navaglia F, Belluco C, Falda A, Fogar P, Greco E, Gallo N, Rugge M, Di Mario F, Plebani M (2005) Pro- and antiinflammatory cytokines gene polymorphisms and Helicobacter pylori infection: interactions influence outcome. Cytokine 29: 141-152 